\title{
HOW WE FAILED TO PLAN FOR HABITABILITY
}

\author{
Lee Lik Meng ${ }^{1}$, Aldrin Abdullah, Tan Sook Fern, \\ Nurwati Badrulzaman and Ahmad Sanusi Hassan \\ School of Housing, Building \& Planning \\ UNIVERSITI SAINS MALAYSIA
}

\begin{abstract}
A quality housing development should not only take into account the physical aspects of design but also be sensitive to human needs. Habitability in housing involves several components, including environmental factors, man-made designs, socio-cultural operations and psychological impacts. Elements of habitability can be observed in various concepts of residential developments including classical concepts such as the Garden City Movement and the Neighbourhood Unit. In Malaysia, the Malay Kampung and the Chinese New Village exemplify some ideal living practices relating to habitability. Both the classical and traditional concepts influenced subsequent residential developments in Malaysia such as the Jengka Project, Kampung Tersusun, Town 8, Cyberjaya and Putrajaya. However, not all residential developments succeeded in creating a quality living environment. More recent concepts such as the New Urbanism and the China Healthy Residence have placed greater emphasis in dealing with such issues. In Malaysia, legislations and policies have not adequately addressed the problems on habitability. We lack a thorough planning system, which prepares and monitors the quality of our residential development. Failures in planning policies have also created other planning issues that affect habitability, as portrayed in the case of the Rifle Range Low-cost Flats in Penang. The top-down approach in housing policy and planning should be geared up to match the growth of community towards achieving habitability.
\end{abstract}

Keywords: Habitability, Housing, Legislation, Public Policy

\section{INTRODUCTION}

Habitability is a subject that concerns people, buildings and the environment. Conceptually, habitability refers to the condition of a building, i.e. residential, where people inhabiting the dwelling unit are free from defects that may be harmful to their health and safety. Specifically, habitability means housing that provides people a needed space to live in dignity and peace, and as a protection

${ }^{1}$ Assoc. Professor Dr. Lee Lik Meng can be contacted at lmlee@usm.my 
from the natural elements, structural hazards and disease vectors which threaten their physical well being. The physical conditions of habitability can affect the realization of other human rights, including the attainment of high standards of mental and physical health. Habitability ensures that the dwellers live in a healthy, safe and comfortable environment, which helps develop a positive identity.

Housing is an integral element in planning for habitability. A housing unit is the smallest building unit in a housing development. Dwellers of a group of housing units of similar built and character make up a community. A community constantly interacts with other communities through a framework of planning aspects to achieve an orderly living environment. Community interaction is enhanced through recognition of the principles of habitability, i.e. safety, health, mobility, sustainability, convenience and accessibility. Specific indices are identified based on these principles to gauge the quality of the living environment. Housing is associated with other planning aspects such as population, socio-culture, economy, land use, infrastructure and utility, health consideration, mobility and governance (refer Figure 1). Good coordination among these aspects leads to a habitable housing development.

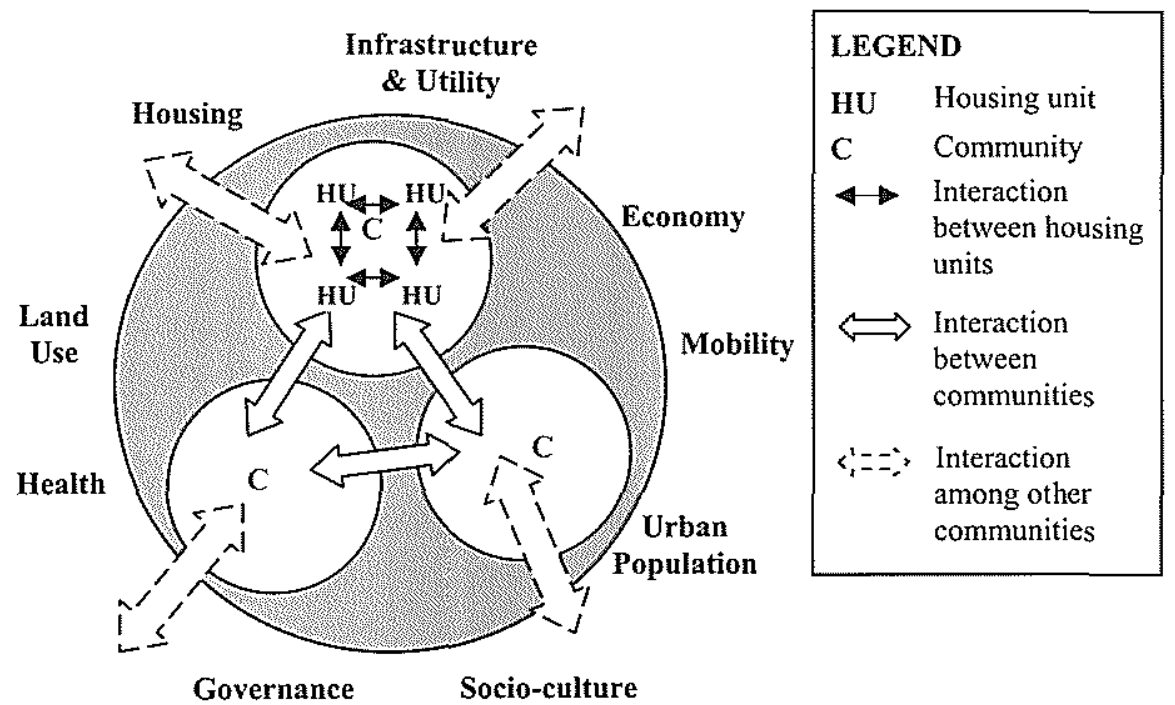

Figure 1: Town Planning and its Components

(Source: Modified from Indicators of Sustainable Development in Industrializing Countries, Vol. III: Key Indicators for Tropical Cities) 


\section{HABITABILITY ELEMENTS}

Generally, there are two major elements in habitability extending from the identified principles and indices. The first element is the physical factor comprising of the natural considerations and the man-made aspect. The second element is the human factor, which consists of the socio-cultural and psychological aspects. All these elements and factors are inter-related as shown in Figure 2.

TOWN PLANNING

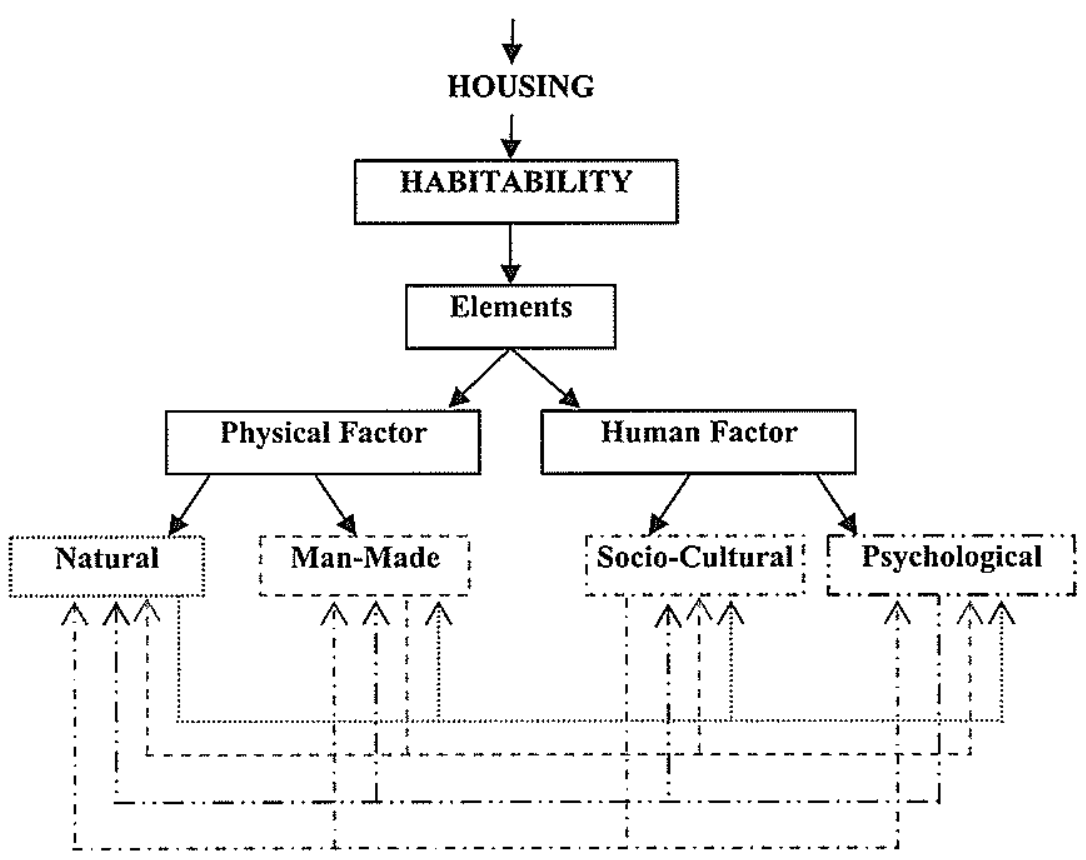

Figure 2: A Model of Habitability and other Related Components of Planning

The physical factor consists of two components. The first component is the natural aspects. In this regard, it is essential to design for a housing development that minimizes the destruction of natural resources. The housing design should adapt to the natural elements such as trees, rivers and hills, and should preserve the greenery to maintain a balanced ecosystem. Safeguarding the natural resources in housing development is an effort towards mitigating potential environmental hazards. Damage inflicted upon nature and the ecosystem is irretrievable. Humans are faced with the consequences of 
ultraviolet and radioactive exposures, ozone depletions, high lead compositions, electromagnetic interruptions, temperature increase, flooding, landslide and other pollutants. Such hazards affect our living condition and habitability appears to be a distant ideal. On the contrary, a housing development that considers the natural elements will extend a harmonious relationship between human and nature.

The second component is the man-made aspects, which refer to the allocation and design of space, construction works and other non-natural considerations that contribute towards creating a habitable environment. These man-made aspects include colour scheme, building materials, views and vistas, lighting and illumination, heat and humidity control, ventilation, fire protection, hygienic consideration, design for privacy, basic infrastructure and amenities, landscaping and furniture arrangement. Taking into account the associations between the man-made aspects, health as well as other psychological influences, the man-made aspects are measured scientifically to establish parameters of a living condition that satisfies the principles of safety, health, accessibility, mobility, sustainability and user-friendliness. Reducing a man-made design into simplified calculations is a quick and easy way to establish a standard of habitability for practical applications, especially in legislations. Some examples include determining the density of a dwelling unit by the family size; safety and security of a house by the cases of reported thefts; and the mobility in a house by the design and use of space.

There is also the human factor in habitability comprising the socio-cultural and psychological aspects, which relate to people and their activities that affect the quality of a living environment. In socio-cultural aspects, the social needs of the people are a prerequisite in habitability. It reflects the nature of the clusters and patterns of relationships that exist within the community. People often communicate and interact through a medium of a common language, norm, culture, and shared expressions. Such interactions extend from a family unit to a neighbourhood and to the entire community; a process that eventually builds a lucid image and identity of a community of similar socio-cultural backgrounds and values. Having a sense of community helps promote a cheerful spirit of sharing and caring among members of the community. A sense of belonging in a community enhances the peoples' capacity to build a habitable environment. A good example is the Malay Kampung where villagers often demonstrate their kampung spirit through voluntary activities such as kenduri and gotong-royong.

Profound changes in the social structure have witnessed a change in family patterns and lifestyles. The number of extended families sharing the same 
household has dropped. This situation has reduced the household size and alters the space needs in a house. It is also common for people to share out a house to reduce the burden of high rent or to avoid the high costs of owning a house. Transformations in the social structure, values and lifestyles in the light of economic growth and modernization have made an impact on planning for habitability. Community needs are changing and the pursuit of quality life more demanding, parallel to technological advancements and the influence of human rights.

The psychological aspects in habitability refer to the dwellers' inner responses toward the design and space arrangement of a residential building and the environment. Such inner responses could be positive or negative depending on the individual concerned. Positive responses, i.e. happy, safe, secure, healthy, relax and dynamic, help shape a better living atmosphere which subsequently improves personal development, enhances family relationships, and extends the warmth and friendliness to the whole community. On the contrary, negative responses register a bleak outlook on habitability. Examples of the negative responses include fear or insecurity towards crime, height and darkness; pressure from poor colour scheme, décor, space limit, noises in the living space, a lack of comfort and of privacy. Negative responses are more apparent among dwellers of residential areas or housing units that do not meet certain habitability principles. Other negative influences of a psychological nature relate to the impacts of environmental hazards and disasters. Disaster-related damages not only cost the lives of loved ones and personal property, but the realities of the aftermath are often beyond healing. From a psychological viewpoint, habitability can only be achieved when there are positive responses and reactions towards a living environment.

While the physical factor considers the realm of a scientific measurement of space to reach a habitable target, the human factor examines the needs and responses of the various groups of people in pursuing habitability. In essence, the design of space, preservation of natural resources, maintenance of the physical environment, and consideration of social and psychological needs should be incorporated in a proper framework that aims towards creating a habitable living environment.

\section{CONCEPTS OF RESIDENTIAL DEVELOPMENT}

Planning literature has highlighted substantial theories and concepts related to housing and housing development. An overview of the various concepts of 
residential development in planning history would facilitate an understanding of the habitability elements being adapted in housing development.

\section{Classical Residential Concepts in Town Planning}

There are two major classical concepts of residential development in the history of town planning. The first is the Garden City movement inspired by Ebenezer Howard at the end of the $19^{\text {th }}$ century. The garden city concept reflects a selfsufficient satellite town that emphasizes a close relationship between human settlement and nature. In Howard's plan there was a greenbelt linking the city and the countryside. Trees were planted, and shrubs and greenery were in abundance to provide the residents a pleasant and comforting view of the environment. Howard's underlying philosophy was to raise the standards of health and comfort among the workers regardless of grade.

Howard's garden city was not physically built until Raymond Urwin and Barry Parker designed the first garden city at Letchworth. Howard's garden city concept was much enhanced in their design. The core of the concept was focused on creating a harmony between human settlement and the natural elements such as sunlight, greenery, view and vista. Such integration of the natural elements has turned the garden city concept into a creation of social reform for squalid cities. Since then the garden city movement had established a vast influence towards subsequent residential planning worldwide.

Another classical concept of residential development is the neighbourhood unit developed by a social worker, Clarence Perry. Perry put forward some ideas derived from the famous layout of Radburn, which stressed on the segregation between the movement of vehicles and people. According to Perry, there are six principles underlying a neighbourhood unit design. They are:

i. The size should be related to the catchment area of an elementary school.

ii. The residential area should be bounded on all sides by arterial streets and there should be no through traffic.

iii. There should be ample provision of small parks and play area.

iv. There should be a central point to the neighbourhood containing schools and other services.

v. District shops should be located on the periphery, thus serving approximately all neighbourhoods.

There should be a hierarchy of streets to facilitate access but through traffic is discouraged. 
The design principles addressed by Perry underline a key element in habitability- that all residential development should pay attention to the connections between various activities that take place within a housing area in order to provide maximum convenience to its residents. Furthermore, the design of road networks should emphasize both accessibility and safety of the users. Another habitability element found in this concept is the recreational activities which provide space for the residents to be acquainted and to appreciate the natural resources. In short, the concept of neighbourhood unit cultivates a sense of a healthy community among its residents.

\section{Residential Concepts in Malaysia}

Various residential concepts, both traditional and modern, have been observed in Malaysia's unique, multi-cultural residential landscape. It is noteworthy that different races of distinct cultures and lifestyles are portrayed in the residential concepts of the Malay Kampung and the Chinese New Village. This section discusses these two unique residential concepts in relation to habitability. This is followed by an overview of selected residential development schemes in Malaysia in their attempts to incorporate some elements of habitability.

\section{i) Malay Kampung and Chinese New Village}

A Malay Kampung is a traditional settlement which emphasizes friendly and habitable design that adapts to the natural environment. In a traditional kampung, four houses will normally occupy one acre of land; therefore the density of a Malay Kampung is relatively low. The Malay houses are usually built in groups. Each group consists of a core house surrounded by several subgroups of houses.

A traditional Malay house usually has a kitchen, a living room and a bedroom. But there is always a reserve plot for expansion to accommodate future children. The toilet and bathroom are built at a distance from the house for the indigenous villagers think these spaces are dirty areas. Some houses have narrow bridge ways as a transition area between the so-called clean and dirty areas. This design concept explains how the villagers deal with the hygiene aspect since there was no centralized sanitary system in the old days. However, a modern Malay house today is well equipped with basic infrastructure, and so the bathroom and toilet are no longer separated from the house.

A Malay house is also well-known for its stilt design. The structure is built in such a way to avoid flooding and to separate the ground level from the house for hygienic reason. The building material used is not 
heat resistant like attap roof and wooden wall. The planting of trees and shrubs provides adequate shading and ventilation around the house. Moreover, the trees and shrubs play an important role in marking the boundary of each house, which however are being replaced by fences and walls in some kampung. Another unique attribute of a Malay Kampung house is the orientation of the building unit from southeast to northeast for religious obligations. Such an orientation is beneficial in avoiding direct sunlight, thus reducing the heat trap in the house. Until today it is uncommon to find an airconditioning system being installed in a Malay house. The welldesigned Malay Kampung house which adapts to the environment illustrates a fine example of the physical factor in habitability.

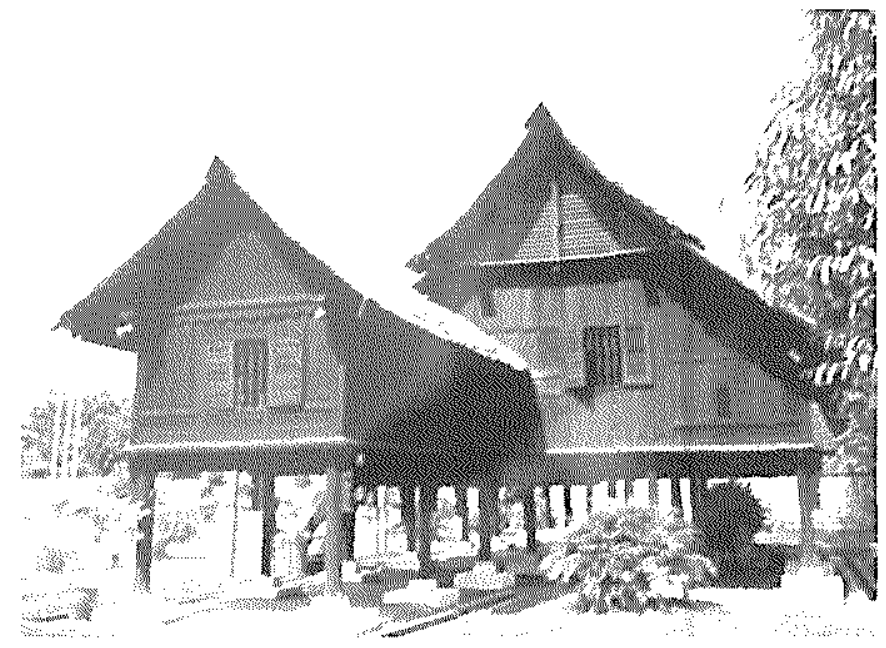

Figure 3:'A Malay house on stilts.

(Photo by Ahmad Sanusi Hassan)

A Malay Kampung also incorporates the human factor in habitability. The kampung lifestyle is based on customs and mutual ties among the households. Residents normally share a kinship, which is extended from the core house to its subgroups. Rapport among the villagers is formed rather easily. Although the scatter pattern is typical of a Malay Kampung, there are often some focal points like the mosque, community hall, shops and neighbourhood courtyard which bring the villagers together. The villagers interact with each other to a high degree through regular activities held at these focal points. From their daily contacts, the relationships and a sense of belonging among the villagers grow stronger. This is evident in the villagers' cheerful 
cooperation during a feast or khenduri; or when faced with hardship, the neighbourhood bond offers protection and a helping hand.

The Chinese New Village is another unique concept of residential development in Malaysia. Formed during the Emergency Period (1948-1960), the Chinese New Village was a mega resettlement project headed by General Sir Harold Briggs. There were four prerequisites under the Briggs Plan. Firstly, the new villages were to be built on or near the main road and their locations to be economically viable. Secondly, only six houses were allowed on per acre of land. Thirdly, new agricultural land within two miles of the new villages was to be prepared for farmers who had abandoned their homeland. Lastly, estate workers who were relocated to the new villages could work anywhere within two miles of the new villages. Most of these villages were equipped with basic amenities including police station, clinic, primary school, community hall, basketball court, field, temple and an area for animal rearing. Interestingly, the four prerequisites specified for these villages had underpinned some of the habitability considerations such as accessibility, density and social operations, although they were shrouded with political ramifications. However, since the resettlement decision was done in haste; these villages were not as organized.

Some elements of habitability are evident in the Chinese New Village. Houses located in the Chinese New Village are mostly single dwelling units. Normally these houses have passageways along the side. There is usually a big compound in the front or in the rear of the house where the villagers' rear domestic fowl or plant flowers, vegetables and fruit trees. Fowl, vegetables and fruit from the compound provide food for the household. In addition, the fruit trees provide shading to the compound and the house. This factor explains why a typical village house is relatively cooler than a modern house, which does not usually grow big trees in its compound due to a lack of space. The compound is also used as a place to dry clothes or to air the cocoa seeds. It is a pleasant place to relax where the elderly could get together for a chat, while the children play under the shady trees.

Another important element of habitability found in the Chinese New Village is self-initiative. Most of the Chinese New Villages have set up their own committees to carry out various programmes; for instance, village beautification, tuition class, neighbourhood watch and voluntary fire brigade. Most of these programmes have been 
successful, which further portrays the villagers' spirit of cooperation in taking charge of their living environment. The spirit of participation in the Chinese New Village is a good example of town planning practices that sustain and contribute towards achieving habitability.

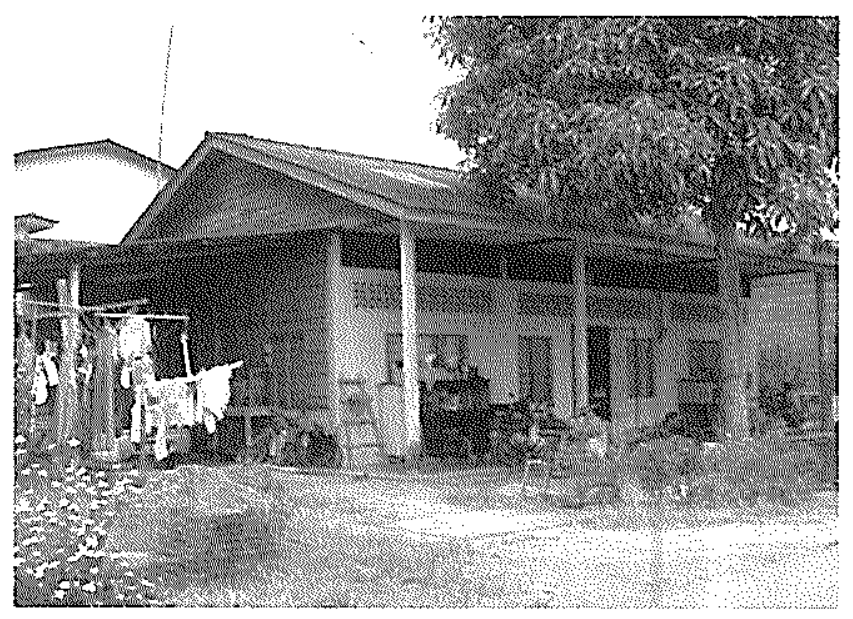

Figure 4: A typical Chinese New Village house with a big courtyard. (Photo by Tan Sook Fern)

However, most of these activities are fast diminishing in the Chinese New Village today. Many villagers have rebuilt, renovated and extended the floor space of their houses. Trees were felled and grounds were cleared for maintenance and hygienic reasons. As a paved surface is relatively easy to maintain, many villagers have paved their grounds and built walls or fences around their house. A drastic change in the housing appearance, from soft landscaping to hard surface surround, has created a sense of rigidity that undermines the character and identity of housing in the Chinese New Village. Today, most of the Chinese New Villages are stirring with problems including a lack of upgraded amenities and maintenance, and a lack of governmental response. While some of the Chinese New Villages are rather crowded due to a high population growth, some other villages especially those in the rural areas are experiencing a steady population decline. The generally poor living condition prevalent in the Chinese New Villages has affected the levels of habitability in this area. 


\section{ii) Rural Residential Schemes and New Towns}

Shortly after independence in 1957, Malaysia carried out various housing development policies such as the rural residential schemes and new towns to cater for a growing populace. Programmes for rural development began in 1956 with the formation of the Federal Land Development Authority (FELDA). FELDA, the country's largest land development agency has developed a regional-level settlement scheme called the Jengka Triangle Regional Land Settlement Project in the east coast of Pahang. The Jengka settlement comprises several villages surrounded by plantation, which is the villagers' economic resource. A town named Bandar Pusat, equipped with school, mosque, clinic, social welfare and other basic infrastructures was established to provide service for the surrounding villages.

From a habitability perspective, the Jengka settlement has not been successful in providing a quality living environment. A major reason is that the traveling distance between Bandar Pusat and the surrounding villages is too far. Furthermore, the range of goods and services offered at Bandar Pusat is limited and unsatisfactory compare to the other towns. Convenience was supposed to be an important measure in providing services and amenities to the settlers, but apparently the planning of the Jengka settlement has overlooked the social needs of its residents. The Jengka situation may be highlighted as a successful exploitive example for forest clearing, but it has inadvertently failed to develop as a planned, convenient and sustainable settlement that attracts people to stay.

Apart from Jengka, there are other rural settlement projects spearheaded by various state agencies, namely Ketengah, Kesedar, Keda, Perda and Kejora. Concerned with reorganizing and improving the living conditions of existing villages, these state agencies have introduced several residential concepts to achieve their goals. The concept of Kampung Tersusun, for one, explores a planned village setting based on several categories or conditions such as a village resettlement, a new village located on government-granted land or a village rearrangement in lieu of natural disasters. Kampung Tersusun focuses on enhancing the socio-economic livelihood and welfare of the villagers. Villagers are encouraged to be involved in other economic activities instead of agriculture. Kampung Tersusun is a low-density type development and is well equipped with social services and basic infrastructure. 
Judging by the efforts of the authorities, more rural areas are being developed as new residential settlement. However, several questions linger. While Kampung Tersusun may become a productive and progressive village, what is the true character and identity of this kampung? Is the theory of economic growth and development being introduced indiscriminately in a kampung? Will the concrete jungle replace nature, the air-conditioning system replace the natural breeze, and automobile noise faults the serenity of the kampung? When traditional villages are converted into a Kampung Tersusun, what are the resources at hand for the people to sustain and develop?

The controversy surrounding such housing development often relates to the sustainability issues. It is not easy to achieve a balance between them, particularly when policy makers impose a new housing model in an existing residential area. It is quite problematic to gauge the impact 10,20 or 50 years down the road. It may help residents to solve their current issues but in the long term, it may create new issues. Moreover, are the residents ready for change? It is crucial that policy makers listen and discuss with the affected residents to understand their needs and concerns. Otherwise, one thing is for sure, this development trend would inevitably weaken the identity of the local settlement patterns and affect the character of the housing development. Sustainability in housing is often a victim of development. When a place is not sustainable, it is hard to pursue a habitable environment.

New town is another settlement concept introduced in many urban or suburban areas in Malaysia, especially in the Klang Valley. When the State Economic Development Corporation (SEDC) started their plans for the new town development in 1964, it was based on the concept of self-contained development inclusive of the industrial zone, housing, public services, infrastructure, commercial and administration. Town 8 is an example of new town residential development in Malaysia. Located in Development Authority of Pahang Tenggara (DARA), Town 8 is designed to reduce the monotony of town life by allowing a flexibility of choice among migrants. There are three organizational levels in Town 8, namely the kampung, neighbourhood and town which decide the allocation of public facilities and utilities. The hierarchical arrangement concentrates on the basic infrastructure services and the prevention of resource wastage. The organized levels also facilitate the planning of transportation network that consists of pedestrian pathways, bus routes and road networks. This is to ensure 
smooth traffic movements between the home and work place or other facilities, as well for the flow of goods.

The linear layout of Town 8 highlights a design concept based on segregation between the pedestrian and vehicular movement. An appropriate distance between home and work place and other facilities is emphasized in order to reduce energy usage and traveling time. The design of Town 8 shows the central spinal axis is under half a mile while the axis is within half a mile distance. In addition, the area has been zoned such that each zone focuses on a main activity with supporting amenities and services such as sport centre, open space, library, shops, etc.

In Town 8 , similar dwelling units are clustered and an industrial site is established near the town to provide jobs for the residents. Social consideration is one of the criteria used to decide the micro development around the town. This shows that the residential pattern, structure, trend and norms in the community play an important role in shaping a livable and dynamic environment. Overall, Town 8 attempts to create a habitable environment based on the principles of safety, mobility, health, convenience and the social needs of its residents. It stresses on the hierarchical functions at the residential level and supports an integrated transportation system to serve the residents better. However, not every concept works in reality. A main cause for this is the attitude of the end users, that is, the residents' poor acceptance towards the concept applied. With better public empowerment and participation, planning for habitability in the residential areas will make substantial progress.

\section{iii) Mixed Development and Intelligent Township}

Another residential concept introduced in the country is mixed development where the residential area becomes the main supporting activity to other functions such as industry and administration. Examples include the newly developed towns of Cyberjaya and Putrajaya. Claimed as the first intelligent city in Malaysia, Cyberjaya is well equipped with the latest in information technology infrastructure and facilities. The development concept of Cyberjaya emphasizes an eco-friendly principle. Vast natural areas in Cyberjaya have been reserved as a recreational place for the residents. Green areas and related public services encompass about $50 \%$ of the total area development, which was designated as a flagship zone for recreation. Apart from the flagship zone, there are three other major 
zones in Cyberjaya, namely the enterprise zone, the commercial zone and the residential zone.

Located a short distance away from Cyberjaya is the new town of Putrajaya, Malaysia's new administrative capital. Putrajaya's development concept is based on a combination between the garden city and intelligent township. One third of Putrajaya's land area comprises parks, wetlands, gardens and lakes. The development of Putrajaya is made up of a core and a peripheral area. The core or the focal point of Putrajaya house most of the government ministries, departments and agencies, along with other predominant economic activities and social needs. The layout of the core area resembles a formal axis punctuated with nodal features and identifiable precincts.

The peripheral area of Putrajaya is mostly residential, with a projected total of 67,000 housing units catering for residents of various income levels. The residential concept of Putrajaya aims to nurture a sense of identity among the community through the establishment of neighbourhood focal points, public realm and landscaping. A sense of the local identity is developed through the promotion of local flowers, design of street furniture using local images, and the creation of open space of an Islamic influence. Reforestation and enhancement of the natural landscape are encouraged to preserve a scenic view. Various policies and legislations are imposed on the building facade and area to maintain the housing identity and to ensure the land uses contribute to enhance the aesthetic quality of the site.

With regards to the socio-cultural aspect, the authorities including Perbadanan Putrajaya and Putrajaya District Police have undertaken a neighbourhood watch programme in the residential areas to encourage social integration. Through this programme, residents are able to help curb crime and related unhealthy activities in their neighbourhood. Moreover, the intelligent township of Putrajaya is equipped with the smart home concept, intelligent building, intelligent transportation and teleservices. The intelligent concept has been claimed to provide for more secured housing with automated home appliances that respond quickly and efficiently during an emergency. Residents are also able to access the public services and utilities through an integrated electronic community. Above all, the intelligent buildings in Putrajaya are cost effective and environment-friendly. 
Interestingly, both Cyberjaya and Putrajaya new towns emphasize the intelligent concept with high technology input. Yet, at the same time their layout design claim to be adaptable to the natural elements. Technically, the planning concept of both towns is quite similar and both are impressive in terms of nature preservation and technological advancement. But the main function of the towns is not residential development. Several issues are raised. Firstly, how appropriate is it to plan a residential area in proximity to a government administration centre or a high technology development corridor? Secondly, does an intelligent concept make a habitable living environment? Thirdly, both towns claim to be eco-friendly but the construction of hard surfaces is prevalent all over the towns. This situation seems contradictory to nature preservation. Lastly, to what extend does the planning of Putrajaya look into the social needs of the resident of various income levels? How well do the residents maintain their unique lifestyle of a multicultural country?

There is much skepticism concerning the development of Cyberjaya and Putrajaya in achieving the habitability target. One of the possible explanations is that these are pioneering projects in an era of technology. But it is feared that the residents of Putrajaya are generally not ready to make dramatic changes in their lifestyles. As our Prime Minister, YAB Dato' Seri Abdullah Haji Ahmad Badawi has commented, we are a country with first class infrastructure but with third class mentality. It is hard to make progress in planning for habitability without the people's willingness to change their mentality.

\section{Emerging Concepts}

In the light of rapid urbanization and changing lifestyles, many issues regarding the quality of a living environment have emerged. The critical situation has raised awareness among the community. More people have spoken out in response to the habitability issues such as poor quality of living environment, and disasters caused by human ignorance and improper development. These responses have reflected poorly on the quality of our residential development and living habits. In line with these responses, concepts that seek to build a humane living environment have emerged in order to upgrade the monotonous, unfriendly and unsustainable living conditions.

Among the emerging settlement concepts, New Urbanism is a concept of residential development that reacts to problems of sprawl and promotes a return to traditional town planning. First coined by Peter Katz in 1992, the New 
Urbanism movement had gained attention from the academia and researchers as an alternative to solve urban sprawl and develop a more habitable environment.

There are five inter-related core principles of the New Urbanism. Firstly, pedestrian-friendly and connectivity in a smart transportation design. The use of cars is de-emphasized to create a safe and friendly pedestrian environment. The suggested walking distance in a walkable environment is about 10 minutes. Secondly, the mix and diversity principles are emphasized in the settlement areas including neighbourhood, town or city. A settlement area should contain a diverse range and balanced development of housing, jobs, open space and activities like shopping, recreation and entertainment, which provides its residents the daily social services. Thirdly, New Urbanism promotes quality architecture and urban design. The aesthetic qualities of the built environment provide not only comfort and convenience to the people, but also create a sense of place. Fourthly, the traditional neighbourhood structure is the inspiration that contributes to the crux of New Urbanism. The public space is placed in the centre so that everyone can have access to it, easily and conveniently. The fifth principle of New Urbanism is sustainability, which suggests a minimal impact on the environment and an energy-efficient development. In addition, New Urbanism has developed other principles to deal with issues of affordable housing, urban sprawl and historic restoration.

While the New Urbanism concept has emerged in the west, a new holistic housing concept has been introduced in China. The National Residential and Living Environment Project Centre has coined the new housing concept of a Healthy Residence at the start of the new millennium. The Healthy Residence concept has been promoted throughout the major cities in China especially after the widespread incidence of severe acute respiratory syndrome (SARS). People in general have become more conscious and concerned about the health issues and have resumed a more healthy lifestyle.

The basic aspects of the Healthy Residence concept have underlined some principles of habitability. Firstly, the physical condition of the residence incorporates the best qualities of the outdoor and indoor living space in terms of air composition and measures of heat, noise, water, illumination and light. Secondly, an environmentally-friendly approach is emphasized in the housing design to maintain a balanced ecosystem and to avoid natural disaster such as flooding, green house effects, air pollution, etc. Thirdly, the Healthy Residence concept touches on the maintenance of the living condition. Varying levels of standards have been established for a public space or a private space. Among the main focuses are the visual elements, such as colours, building arrangement, advertisement and signage. These visual elements should abide by a certain 
building control in order to maintain their identity and harmony within the community. Other elements include sanitary and sewerage system, water supply, garbage and environmental hygiene. The final aspect in the Healthy Residence concept is the assurance of a healthy living environment. These elements include the mechanisms involved in organizing a quality medical system and services, facilities for the aging, public participation in health consciousness and cultural cultivation.

From the review of the various housing development concepts, it is evident that the focus of habitability is not only the building per se but also the people and the environment. The difference between traditional residential patterns and other modern residential concepts is their lack of locality or identity. The racial identity and their unique lifestyles have been fading amidst rapid urbanization and modernization. Malaysia's multicultural spirit is also changing in the face of a western influence in lifestyles and housing layout. Some people still have a reminiscent for a less organized kampung living while others praise the more organized form of modern housing development. The different responses bring up a pertinent question. Which type of development is more superior and more suited for Malaysians today? It is hard to get a definite answer because there are many pros and cons of the different housing development, yet all these concepts still have rooms for improvement.

\section{LEGISLATIONS AND PUBLIC POLICY}

Basically, legislation relating to habitability covers various aspects such as land use, basic infrastructure, building design, transportation system, nature preservation, environment quality, landscape design, fire safety and rescue, governance in contract, application process, land title and ownership for housing. These are covered under the Local Government Act 1976 [Act 171], Town and Country Planning Act 1976, Street, Drainage, Sewerage and Building Act 1976, National Land Code 1965, Housing Loan Fund Act 1971, Environmental Quality Act 1974, Public Housing By Laws 2002 and Building By Laws 1985. However, there are differences in practice as different government agencies such as the local authorities have different practice.

The legislation for habitability is more focused on the physical housing development rather than socio-cultural aspects. Most of the guidelines are based on density and population size in deciding housing design, layout and the provision of public amenities. For example, in Shah Alam, a 0.5 acre children playground should be prepared for every 500 residents while a 50 acre town park should be provided for 50,000 residents. The suggested room number in Melaka for a household size of 4.6 is set at 4 . In Penang, $10 \%$ of open space 
must be allocated for every low cost flat development which is bigger than 1 acre or more for recreational activities.

The numbers game in the existing guidelines and standards become the basic calculation for housing design and amenity preparation. However, do numbers really help to decide the real need of the community? What if the numbers of the residents are less than the specific standards? Does that mean that those residents cannot enjoy similar facilities? As most of our laws were adapted from Britain, we should argue the suitability of these laws and guidelines for use in our local context.

There are many examples that show that numbers and figures in guidelines do not work out and contribute to a quality living environment. A good example is the lack of parking spaces in many high rise apartments especially in medium low cost or low cost housing area. In Penang, it is very common to see cars parking illegally along narrow roadside next to the apartments. This has become an issue because the rigid guidelines used in preparing the number of parking lots for every apartment or flat do not take into consideration development and growth of society. The guidelines that are employed are not revised to meet the changing needs of the society. For example, it is very common now to find that a housing unit is shared by a group of working people with individual vehicle ownership.

In addition, legislations do not cover the maintenance of a housing development. No monitoring is carried out in a continuous manner to check on the quality of a housing area after being built. For example, the quality of hygiene in many low cost apartments is poor because there is a lack of appropriate management. This causes the spread of diseases such as dengue and created a bad image for the housing area.

Apart from legislations, public policies or strategies in housing are mainly focused on affordability rather than habitability. From the previous actions of the Ministry of Housing and the Local Government lead by Y.B. Dato' Seri Ong $\mathrm{Ka}$ Ting, a lot of amendments and suggestions on housing are made especially on the issue of low cost housing. The ministry aims to provide sufficient and quality housing but so far, the changes have been rather slow.

In general, the government has set that $30 \%$ of a housing development must compromise low cost units. This is to make sure that the lower income group can also own their own shelter. To make the policy a success, they are supported by other incentives such as fast application approvals. But such an effort does not guarantee that supply meets demand. There are a lot of 
abandoned housing developments or empty units through out Malaysia but at the same time there are places where people are squatting, or complaining of unavailability of shelter.

Do policy makers consider changes of social structure and lifestyle in 20 years to come? A very good example is the Rifle Range High Rise Low Cost Flats in Penang. When Rifle Range was built in 1969, the government agreed to apply the rent and buy concept because most of the residents could not afford to own a house. After paying the rental for 25 years, the Rifle Range residents got their grants and have became owners of the house. When the public low cost housing became private property, a lot of infrastructure and amenity issues begin to surface. As the economic status of the residents improve, they renovated and extended their units illegally causing structural concerns. More vehicles were purchased by the residents and caused massive parking problems. This upgraded group is not supposed to stay in the low cost area anymore because the basic amenities do not cater for them. It shows that the initial planning of Rifle Range did not anticipate structural changes of the community and therefore created problems for today.

\section{CONCLUSIONS}

Habitability is not a short-term achievement. It requires effort from everybody so that a more sustainable, healthy and safe living environment can be built. In this paper, the idea of habitability is elaborated along physical and human factors. The elements explain the inter-relationship of natural aspect, man-made aspect, psychological aspect and socio-cultural aspect in the development of housing that shape a habitable environment. To get a bigger picture of habitability in the housing development, a review on the residential development concepts including the classic residential concepts, the local residential development movements and the emerging concepts are discussed. The last part of this paper talks about the legislation and public policies in Malaysia. The inefficiency of the legislation and public policies in habitability compared to other housing issues like affordability and legal process of buying a house is obvious. The emphasis on the habitability in legislation is not detailed and only touches the surface of the issue. To make our living environment more habitable and achieve more quality, the related issues must be identified. In planning, a long-term concrete goal is needed to make up a habitable environment for people. The top-down policy should meet the need of people while the bottom-up awareness acts as a monitor to the government administration and legislation, to make sure the pursuit of habitability is on the right track. Policies must also be flexible to meet changes of future societies and 
future implementers must also be quick to adapt and respond to changes of societies.

\section{ACKNOWLEGEMENT}

This paper was originally presented at the National Conference on Affordable Quality Housing, 24-26 Nov 2004, Miri, Sarawak. The research was funded by an IRPA Grant under the National Research Programme for Affordable Quality Housing ( $8^{\text {th }}$ Malaysia Plan).

\section{REFERENCES}

\section{Books:}

Abraham, C. E. R. 1982. Microcosms of Malaysian Settlement Patterns: Case Studies of Indigenous Development - Pahang Tenggara Regional Master Plan. Penang: Universiti Sains Malaysia.

Bih, Heng-Dar. 2001. The Power of Space. Taipei: PsyGarden Publishing Company.

Cheng, Lim Keak. 1976. Mengkuang: A Study of A Chinese New Village in West Malaysia. Singapore: NanYang University.

Lim, Hin Hui \& Song, Wan Ying. 2002. 50 Years of Malaysian Chinese New Village. KL: Centre for Malaysian Chinese Studies.

Lowe, Marcia D. 1991. Shaping Cities: The Environmental and Human Dimensions. Washington: Worldwatch Institute.

Ministry of Local Government and Housing. 1967. The settlement structure in the regional plan for the JENGKA Triangle in West Malaysia: An attempt at controlling in-migration of persons from rural to urban centres. Pacific Conf. on Urban Growth, Honolulu, Hawaii.

Ratcliffe, John. 1993. An Introduction to Town and Country Planning. London: UCL Press Limited.

Taylor J. L., Ekroth D. C. HBP, USM and Lembaga Kemajuan Pahang Tenggara. 1975. Pahang Tenggara New Town 8: Final Report. Penang: Universiti Sains Malaysia.

\section{Internet:}

Bahrin T. S., Lee B. T., and Dorall R. F. 1988. The Jengka Triangle: a report on research in progress. In Manshard W. and Morgan B. W. Agricultural Expansion and Pioneer Settlements in the Humid Tropics. Tokyo: The United Nations University. http://www.unu.edu/unupress/unupbooks/80636e/80636E0d.htm\#7.The\% 
20Jengka $\% 20$ Triangle: $\% 20 \mathrm{a} \% 20$ report $\% 20$ on $\% 20$ research $\% 20 \mathrm{in} \% 20$ pro gress (19 Apr 2004)

Chen, Ya You et al. "The Story of New Village". Kwong Wah Yit Poh [Penang]. http://www.kwongwah.com.my/village/vl1.htm (14 Apr 2004)

Dasimah Omar. Urbanisation, Urban Fringe Development and the Quality of Life: Evidence from New Town Development in Peninsular Malaysia. 2003. http://www.planning.sa.gov.au/congress/pdf/Papers/Dasimah.pdf (27 May 2004)

Habitat International Coalition, Housing and Rights Network, Midde East/

North Africa. http://www.hic-

mena.org/14\%20Elements\%20of\%20RAH/05habit.htm (1 Apr 2004)

Kai, Y., Liu, D. W., Zhang, W. H., Zhao, X. et. al. 2002. Healthy Residence

Technical Report 2002. Beijing: National Housing Development Centre.

http://www.build.com.cn/health/health-2002-0.htm (25 April 2004)

LegalDefinition.com. http://www.legal-definitions.com/real-

estate/habitability.htm (1 Apr 2004)

Leshler, Jim. 2000. Online News Hour. Kansas: MacNeil-Lehrer Productions.

http://www.pbs.org/newshour/newurbanism/keypoints.html (3 Apr 2004)

Lucey, Norman. 1973. The Effect of Sir Ebenezer Howard and the Garden City

Movement on Twentieth Century Town Planning.

http://www.rickmansworthherts.freeserve.co.uk/howard1.htm\#sne (1 Apr 2004)

"Malaysian Should Change Their Mind". Sin Chew Jit Poh [KL]. 6 Mac 2003. http://news.sinchew-

i.com/article.phtml?artid $=200303070620 \&$ data $=$ news $(25$ May 2004)

New Urbanism. VA: New Urbanisim.com

http://www.newurbanism.org/pages/416429/index.htm (3 Apr 2004)

Pejabat Daerah dan Tanah Manjung. District Profile: Human

Settlements. http://pdt-manjong.perak.gov.my/ENGLISH/index.html (15 May 2004)

Perbadanan Putrajaya. (2003). Pusat Pentadbiran Persekutuan

Putrajaya. http://www.putrajaya.net.my/ (19 Apr 2004) 
